\title{
GABAergic Input onto CA3 Hippocampal Interneurons Remains Shunting throughout Development
}

\author{
Tue G. Banke and Chris J. McBain \\ Laboratory of Cellular and Synaptic Neurophysiology, National Institute of Child Health and Human Development, National Institutes of Health, Bethesda, \\ Maryland 20892
}

\begin{abstract}
In hippocampus, the net flow of excitability is controlled by inhibitory input provided by the many populations of local circuit inhibitory interneurons. In principal cells, $\mathrm{GABA}_{\mathrm{A}}$ receptor-mediated synaptic input undergoes a highly coordinated shift from depolarizing early in life to a more conventional hyperpolarizing inhibition on maturation. This switch in inhibitory input polarity is controlled by the developmental regulation of two chloride cotransporters ( $\mathrm{NKCC1}$ and $\mathrm{KCC} 2$ ) that results in a net shift from high to low intracellular $\mathrm{Cl}^{-}$. Whether inhibitory input onto inhibitory interneurons demonstrates a similar developmental shift in intracellular $\mathrm{Cl}^{-}$is unexplored. Using the gramicidin perforated-patch configuration, we recorded from CA3 hippocampal stratum lucidum interneurons and pyramidal cells to monitor inhibitory input across a broad developmental range. $\mathrm{GABA}_{\mathrm{A}}$ receptor-mediated synaptic input onto stratum lucidum inhibitory interneurons was shunting in nature across the entire developmental age range tested, as resting membrane potential and the IPSC reversal potential remained within a few millivolts $(1-4 \mathrm{mV})$ between postnatal day 5 (P5) and P31. Furthermore, sensitivity to block of the two chloride cotransporters KCC2 and NKCC1 did not differ across the same age range, suggesting that their relative expression is fixed across development. In contrast, pyramidal cell synaptic inhibition demonstrated the well described switch from depolarizing to hyperpolarizing over the same age range. Thus, in contrast to principal cells, inhibitory synaptic input onto CA3 interneurons remains shunting throughout development.
\end{abstract}

Key words: GABA; synaptic inhibition; hippocampus; interneurons; development; CA3

\section{Introduction}

In the CA3 hippocampus, stratum lucidum inhibitory interneurons (SLINs) receive excitatory drive from both the mossy fiber axons of dentate gyrus granule cells and recurrent collaterals of CA3 pyramidal cells (PCs), as well as being highly interconnected (Toth and McBain, 1998; McBain and Fisahn, 2001; Henze et al., 2002; Lawrence and McBain, 2003). This synaptic arrangement allows SLINs to participate in both feedforward and feedback inhibitory control of mature CA3 PCs (Lawrence et al., 2004). Such inhibitory circuits provide exquisite control over network excitability through surround inhibition and by timing spike generation in principal cell targets (Pouille and Scanziani, 2001; Lawrence and McBain, 2003; Mori et al., 2004).

Although a conventional hyperpolarizing driving force for inhibitory synaptic transmission exists at mature CA3 PC synapses, it is well established that the $\mathrm{Cl}^{-}$reversal potential $\left(E_{\mathrm{Cl}}\right)$ is positive relative to the resting potential early in development, and thus, GABA is excitatory in immature PCs (Ben-Ari, 2002). The

\footnotetext{
Received July 7, 2006; revised 0ct. 4, 2006; accepted 0ct. 4, 2006.

This work was supported by the Intramural Research Program of the National Institute of Child Health and Human Development-National Institutes of Health. We thank Drs. K. Pelkey and J. J. Lawrence for critically reading a previous version of this manuscript and Brian Jeffries for performing the immunocytochemistry and Neurolucida reconstructions.

Correspondence should be addressed to Chris J. McBain, Laboratory of Cellular and Synaptic Neurophysiology, Building 35, Room 3C903, National Institute of Child Health and Human Development-Laboratory of Cellular and Synaptic Neurophysiology, Bethesda, MD 20892.E-mail:mcbainc@mail.nih.gov.

DOI:10.1523/JNEUROSCI.2887-06.2006

Copyright $\odot 2006$ Society for Neuroscience $\quad 0270-6474 / 06 / 2611720-06 \$ 15.00 / 0$
}

shift in $E_{\mathrm{Cl}}$ - results from the differential developmental expression of the chloride cotransporters, NKCC1 and KCC2 (Rivera et al., 1999; Dzhala et al., 2005). The developmental upregulation of KCC2 is considered to be the primary determinant in lowering intracellular $\mathrm{Cl}^{-}$levels. Whether a similar shift in the relative expression of $\mathrm{NKCC} 1$ and/or KCC2 occurs on interneurons during development is unexplored.

Emerging evidence suggests that $\mathrm{GABA}_{\mathrm{A}}$-mediated inhibition of various interneurons is shunting in nature (Martina et al., 2001; Bartos et al., 2002; Chavas and Marty, 2003) rather than arising through hyperpolarization. This would suggest that the rules for synaptic inhibition onto interneurons may not mirror those seen on principal cells. In the present study, we determined the developmental regulation of inhibitory synaptic transmission onto CA3 SLINs. At the resting membrane potential $\mathrm{GABA}_{\mathrm{A}^{-}}$ mediated input was primarily shunting in nature across the entire developmental window studied [postnatal day 5 (P5) to P31]. Furthermore, the magnitude of pharmacologic block of both NKCC1 and KCC2 cotransporters was similar across all ages tested, suggesting that the relative contribution of these transporters to SLIN homeostasis remains relatively fixed throughout development.

\section{Materials and Methods}

Hippocampal slice preparation

Hippocampal slices $(300 \mu \mathrm{m})$ were prepared from P5-P31 (white $\mathrm{FVB} / \mathrm{N}$ ) mice as indicated throughout the text. All animals were anesthetized with isoflurane before decapitation according to National Institutes 


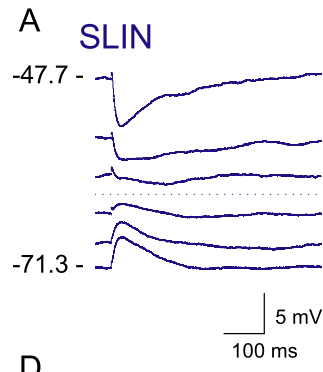

D

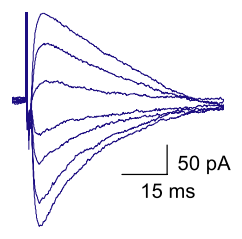

G

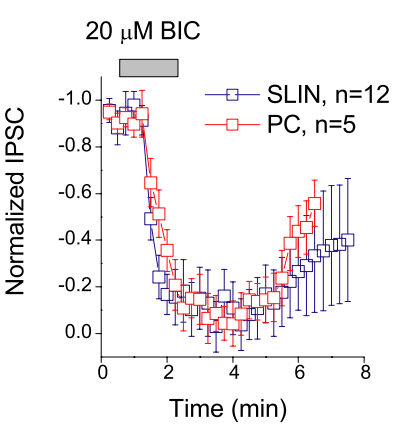

$-23.7-$

$57.4-$

E
B $\quad$ PC
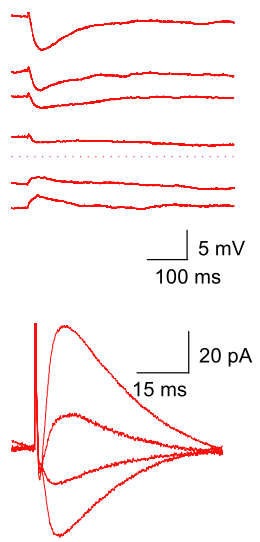

$\mathrm{F}$
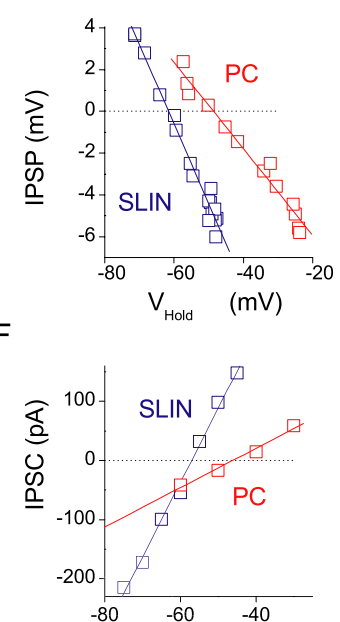

$\mathrm{H}$

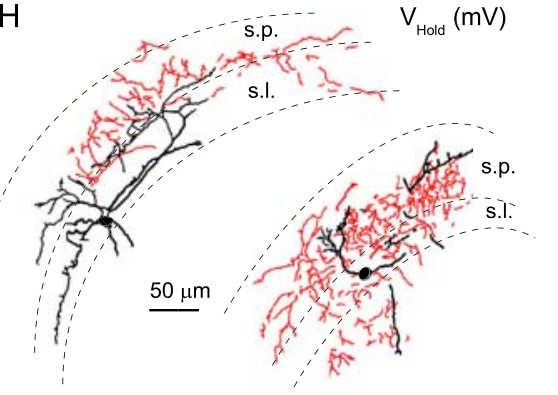

Figure 1. Inhibitory synaptic events evoked onto SLINs and CA3 pyramidal cells. Perforated-patch recordings of representative IPSPS $(\boldsymbol{A}, \boldsymbol{B})$ and IPSCS (D, E) evoked onto an SLIN (P12) $(\boldsymbol{A}, \boldsymbol{D})$ and a CA3 pyramidal cell (P12) $(\boldsymbol{B}, \boldsymbol{E})$. Respective voltage and current-voltage relationships are plotted to the right $(\boldsymbol{C}, \boldsymbol{F}) \cdot \boldsymbol{G}, \mathrm{IPSCS}\left(V_{\text {hold }}=-60 \mathrm{mV}\right)$ were blocked by $20 \mu \mathrm{m}$ bicuculline. Error bars indicate SEM. $\boldsymbol{H}$, Morphological profiles of two representative SLINs, biocytin-filled and reconstructed using Neurolucida. All cells had soma and dendrites principally located within stratum lucidum, pyramidale, and radiatum. The axons (shown in red) primarily ramified throughout stratum lucidum and radiatum and into the stratum pyramidal cell layer. s.p., Stratum pyramidale; s.l., stratum lucidum.

of Health Animal Use Guidelines. Brains were rapidly dissected out and placed in ice-cold saline solution containing the following (in $\mathrm{mM}$ ): 130 $\mathrm{NaCl}, 3.5 \mathrm{KCl}, 24 \mathrm{NaHCO}_{3}, 1.25 \mathrm{NaH}_{2} \mathrm{PO}_{4}, 0.5 \mathrm{CaCl}_{2}, 5 \mathrm{MgCl}_{2}$, and 10 glucose, equilibrated with $95 \% \mathrm{O}_{2} / 5 \% \mathrm{CO}_{2}, \mathrm{pH}$ 7.4. Slices were prepared using a modified Leica (Nussloch, Germany) Vibratome and were incubated at $34^{\circ} \mathrm{C}$ for $\sim 1 \mathrm{~h}$ before their use. Individual slices were transferred to an upright microscope and visualized with infrared differential interference contrast microscopy (Axioscope 2; Zeiss, Oberkochen, Germany). Slices were perfused at $>2 \mathrm{ml} / \mathrm{min}$, using the medium described above, with the exception that $\mathrm{MgCl}_{2}$ was $3 \mathrm{~mm}$ and $\mathrm{CaCl}_{2}$ was $2.5 \mathrm{~mm}$. DL-APV $(100 \mu \mathrm{M})$ and DNQX $(10 \mu \mathrm{M})$ were included to block NMDA and AMPA receptor-mediated transmission, respectively. The temperature of the recording solution $\left(33 \pm 1^{\circ} \mathrm{C}\right)$ was monitored throughout recordings.

\section{Electrophysiological recording}

Perforated-patch recordings. Perforated-patch recordings were made from identified stratum lucidum interneurons or CA3 pyramidal cells. Recording electrodes (4-5 M $\Omega$ ) contained gramicidin (gramicidin ABCD; G-5002; Sigma, St. Louis, MO) (25-50 $\mu \mathrm{g} / \mathrm{ml})$ in a solution comprised of the following (in $\mathrm{mm}$ ): $100 \mathrm{KCl}, 10 \mathrm{HEPES}, \mathrm{pH}$ 7.2. The electrode tip was front-filled with an identical, but gramicidin-free, solution (Kyrozis and Reichling, 1995). Access resistance (Ra) was monitored rigorously throughout experiments and over the course of 20-30 min stabilized at $43 \pm 1 \mathrm{M} \Omega(n=127)$ for interneuron recordings and $45 \pm$ $3 \mathrm{M} \Omega(n=20)$ for CA3 pyramidal cells. Experiments did not commence until the Ra had stabilized. Ra compensation was not applied. All recordings were made with an AXON Multiclamp 700A amplifier (Molecular Devices, Sunnyvale, CA), data were low-pass filtered $(5 \mathrm{kHz})$ and ac- quired at $10 \mathrm{kHz}$ on a standard personal computer. Measurements were not corrected for liquid junction potentials.

In a subset of experiments, Lucifer yellow (5\%) was included in the gramicidincontaining solution and the cell monitored using fluorescent microscopy to confirm that the perforated-patch configuration had not ruptured during the experiment. In a number of experiments after recording in the perforatedpatch mode, a second electrode was advanced to repatch the cell in whole-cell configuration allowing biocytin access to the cell for post hoc morphological reconstruction.

Cell-attached recordings. Cell-attached recordings, to determine SLIN resting membrane potential $\left(V_{\text {rest }}\right)$, were made using a solution containing the following (in $\mathrm{mM}$ ): $120 \mathrm{KCl}, 11$ EGTA, $1 \mathrm{CaCl}_{2}, 2 \mathrm{MgCl}_{2}, 10 \mathrm{HEPES}, 1 \%$ biocytin, titrated to $\mathrm{pH} 7.4$ with $\sim 35 \mathrm{~mm} \mathrm{KOH}$ (free $\left.\mathrm{K}^{+} \sim 155 \mathrm{~mm}\right), \sim 300 \mathrm{mOsm}$. To determine accurate estimations of the neuronal resting membrane potential, we used the cell-attached recording technique (Verheugen et al. 1999) in which depolarizing voltage ramps (from -100 to $+200 \mathrm{mV}$ ) are applied to cell-attached patches to activate voltage-gated $\mathrm{K}^{+}$channels. Given that there is equimolar $\mathrm{K}^{+}$inside the cell-attached pipette and the intracellular compartment, the $\mathrm{K}^{+}$current reversal potential provides an accurate measure of the resting membrane potential of the cells.

Inhibitory synaptic events were activated using short duration, low intensity constant current stimuli (30-100 $\mu \mathrm{A}$; pulse duration, 0.2 $\mathrm{ms}$ ) delivered via a monopolar glass electrode connected to a constant current stimulus isolation unit (World Precision Instruments, Sarasota, FL) placed within the stratum lucidum or at the stratum radiatum border. The frequency of stimulation was typically $0.5 \mathrm{~Hz}$. Current or voltage reversal potential ( $E_{\text {IPSC }}$ or $\left.E_{\text {IPSP }}\right)$ was calculated by a linear fit of the data around the reversal potential (Origin, version 7.0; Origin Lab, Northampton, MA). A Spearman rank correlation was used to test the correlation of reversal potentials with age (see Fig. 2). All data are presented as mean \pm SEM, and statistical significance was determined using paired or unpaired Student's $t$ test as appropriate.

Anatomical reconstruction. For morphological reconstruction, wholecell recording pipettes contained biocytin (1-2\%). Slices were fixed overnight in $4 \%$ paraformaldehyde at $4^{\circ} \mathrm{C}$, permeabilized in $0.1 \%$ Triton $\mathrm{X}-100$, and incubated with Alexa 488-conjugate avidin. Resectioned slices were mounted on gelatin-coated slides using Mowiol mounting medium and imaged using a Leica confocal microscope (TCS SP2RS). Cells were reconstructed using the Neurolucida suite of programs.

Drugs. All chemicals were purchased from Sigma or Tocris (Ellisville, MO). Mowiol was obtained from Invitrogen (San Diego, CA).

\section{Results}

Inhibitory synaptic transmission onto SLINS

Although much is known about inhibitory input onto CA3 principal cells, surprisingly little information exists regarding the basic properties of inhibitory transmission onto CA3 SLINs. To investigate this, we made perforated-patch recordings from visually identified SLINs (Fig. 1), using the cation-specific poreforming agent gramicidin to minimize perturbation of the intracellular anion homeostasis (Kyrozis and Reichling, 1995). Figure 1 shows representative example IPSPs and IPSCs evoked at low frequency $(0.5 \mathrm{~Hz})$ onto both a SLIN and CA3 pyramidal cell in 


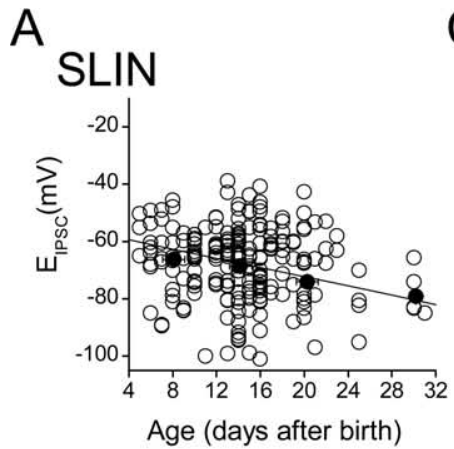

C

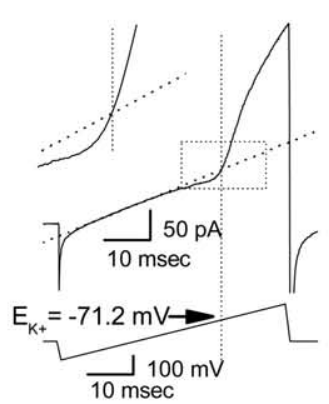

$\mathrm{B}$

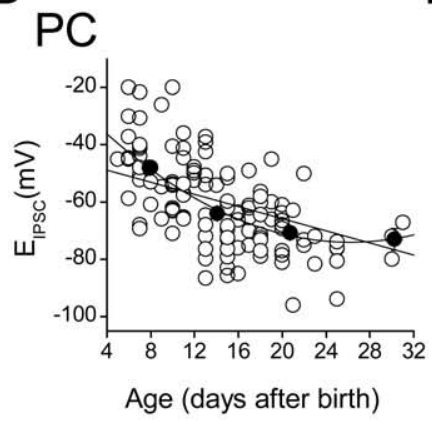

$E$

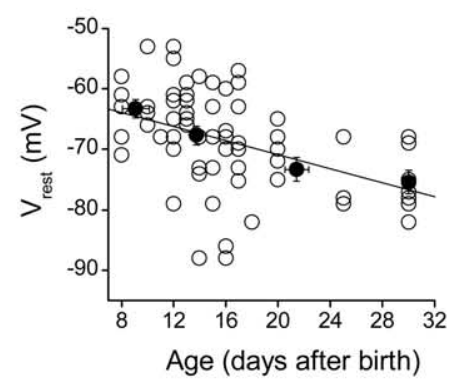

$\mathrm{F}$
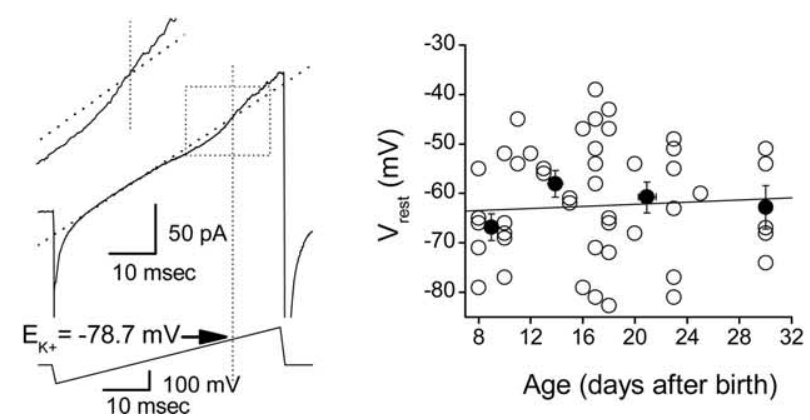

G

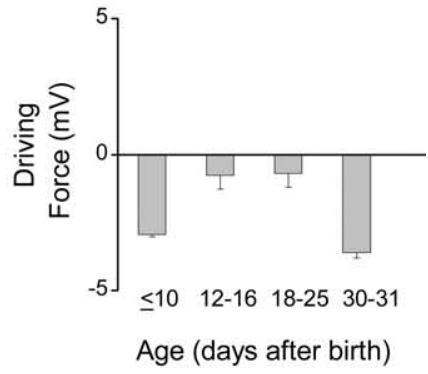

$\mathrm{H}$

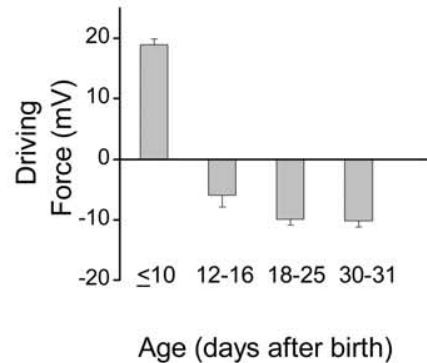

Figure 2. Shunting inhibition onto SLINs persists throughout development. $\boldsymbol{A}, \boldsymbol{B}$, Evoked IPSC reversal potential ( $\left.E_{\text {IPSC }}\right)$ for $S L I N s(\boldsymbol{A})$ and PCS $(\boldsymbol{B})$ measured across different developmental stages. Each open symbol represents the $E_{\text {IPs }}$ obtained from a single recording. Averaged data (black-filled symbols) for each development stage ( $\leq 10,12-16,18-25$, and $30-31$ ) are superimposed on top, and linear fit through averaged data is shown. A second-order polynomial fit to averaged PC data (B) gave a better fit. Spearman rank correlation coefficients were -0.66 and -0.38 for SLINs vs age and for $P\left(\right.$ vs age, respectively. $\boldsymbol{C}, \boldsymbol{D}$, Examples of cell-attached recordings from an interneuron $(\boldsymbol{C})$ and pyramidal neuron $(\boldsymbol{D})$, respectively, used to measure $V_{\text {rest }}$ A linear regression fit to the linear phase (typically fitted between the period $10-25 \mathrm{~ms}$ of the ramp) is superimposed (dotted lines). The bottom traces indicate the corresponding voltage ramp protocol (ramp from -100 to $+200 \mathrm{mV}$ ). The intersection of the vertical dotted line with the linear fit indicates $E_{\mathrm{K}}{ }^{+}$(i.e., the estimated resting potential for this cell), which for the interneuron was $-71.2 \mathrm{mV}(\mathrm{P} 17)$ and for $\mathrm{PC}$ (P18) was $-78.7 \mathrm{mV}$, respectively. The inset for each panel shows this period of the ramp in greater detail. $\boldsymbol{E}, \boldsymbol{F}$, The resting membrane potential of SLINs and PCs across development measured using cell-attached recording configuration. At different development stages (postnatal days $\leq 10,12-16,18-25$, and $30-31$ ), the average $V_{\text {rest }}$ was calculated and superimposed on data and fit with linear regression. $\boldsymbol{G}, \boldsymbol{H}$, Calculation of the GABAergic synaptic driving force $\left(E_{\mathrm{IPSC}}-V_{\text {rest }}\right)$ at the resting membrane potential for both SLINs $(\boldsymbol{G})$ and PCS $(\boldsymbol{H})$. Note that inhibitory events in SLINs have a minimal driving force at all developmental ages tested, suggesting that inhibition is primarily "shunting." This is in marked contrast to PCs, which show a clear polarity shift in driving force after day 10. Error bars indicate SEM.

slices obtained from P12, evoked by placement of a stimulating electrode within the stratum lucidum of CA3. Evoked IPSCs (or IPSPs) from both SLINs and PC were blocked ( $96 \pm 4 \% ; n=12)$ by bicuculline $(20 \mu \mathrm{M})$, confirming they were $\mathrm{GABA}_{\mathrm{A}}$ receptor mediated (Fig. $1 G$ ). At this age, inhibitory events evoked onto SLINs and PCs reversed at different potentials. In pyramidal cells, the mean IPSC reversal potential was $-49.7 \pm 1.0 \mathrm{mV}(n=4$; $\mathrm{P} 12)$ and in SLINs $-63.2 \pm 2.0 \mathrm{mV}(n=13 ; \mathrm{P} 12 ; p=0.004)$ (Fig. $2 A, B)$.

After perforated-patch recording was complete, we subsequently filled cells with biocytin via a whole-cell patch pipette for morphological recovery (Fig. $1 H$ ). Reconstruction revealed that recorded SLINs comprised a morphologically heterogeneous group, all with their cell bodies within stratum lucidum (Fig. $1 \mathrm{H}$ ). Consistent with the known marked heterogeneity of cells in this subfield (Toth and McBain, 1998), cells possessed widely diverging anatomical properties and no one cell type was preferentially encountered.

\section{SLIN IPSCs are not developmentally regulated}

Using the perforated-patch configuration, we next explored the developmental regulation of inhibitory input onto both SLINs and pyramidal cells. The evoked IPSC reversal potential $\left(E_{\text {IPSC }}\right)$ was measured in 225 SLINs and 123 PCs between P5 and P31 (Fig. 2). In SLINs, the mean IPSC reversal potential significantly hyperpolarized over development (Fig. 2A): at P5-P10, $E_{\mathrm{IPSC}}$ was $-66.2 \pm 1.5 \mathrm{mV}(n=52)$ compared with $-78.1 \pm 3.7 \mathrm{mV}$ at $\mathrm{P} 30-\mathrm{P} 31(n=4 ; p=0.03)$. Similarly, $E_{\mathrm{IPSC}}$ in CA3 PCs shifted to more negative potentials with development (Fig. $2 B$ ) as reported previously (Ben-Ari, 2002). At P5-P10, $E_{\mathrm{IPSC}}$ was $-47.3 \pm 2.5$ $\mathrm{mV}(n=32)$ and progressively hyperpolarized during development, ultimately stabilizing beyond P20 at $-73.0 \pm 3.8 \mathrm{mV}$ (P30; $n=3 ; p=0.005)$.

At rest, the polarity and amplitude of the IPSP is determined by the $E_{\text {IPSC }}$ relative to the resting membrane potential $\left(V_{\text {rest }}\right)$. Thus, we next measured the $V_{\text {rest }}$ of both SLINs and PCs using a noninvasive method in cell-attached mode (Verheugen et al., 1999). By applying voltage ramps from -100 to $+200 \mathrm{mV}$ using electrodes containing $155 \mathrm{~mm} \mathrm{~K}^{+}$(Fig. 2C,D), endogenous voltage-gated potassium channels were activated. Assuming the intracellular $\mathrm{K}^{+}$of the cell to be $\sim 155 \mathrm{~mm}, V_{\text {rest }}$ can be derived from the reversal potential of the voltage-gated $\mathrm{K}^{+}$conductance (Verheugen et al., 1999). This technique provides a powerful and accurate way to determine resting membrane potential without perturbing the intracellular environment. The mean $V_{\text {rest }}$ of SLINs significantly changed across the developmental range tested (P8-P30) (Fig. 2E). At P8-P10, the mean SLIN $V_{\text {rest }}$ was $-63.2 \pm 1.5 \mathrm{mV}(n=11)$ compared with $-75.4 \pm 2.0 \mathrm{mV}$ at P30 $(n=7 ; p=0.001)$. In contrast, the $V_{\text {rest }}$ of PCs did not significantly differ across the same developmental age range (Fig. $2 F$ ). 
A
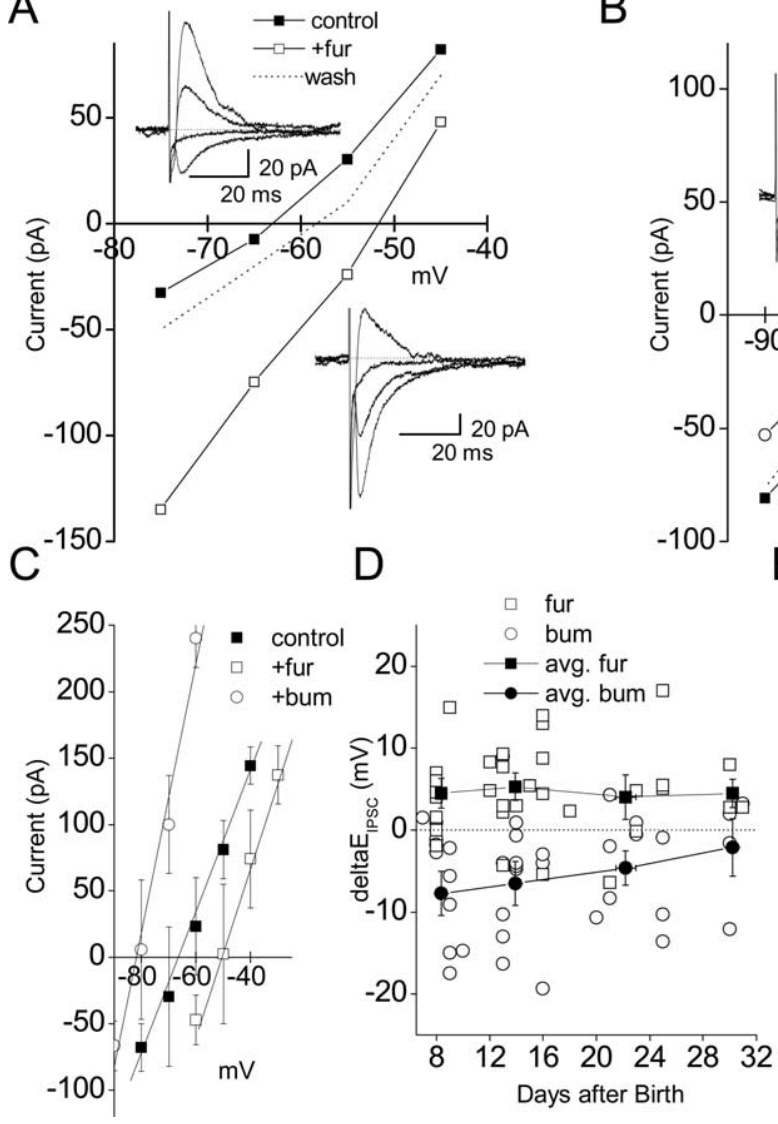

$\mathrm{E}$

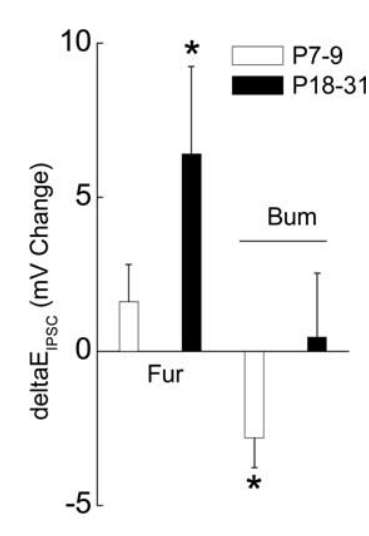

Figure 3. Developmental profile of $E_{\text {IPS }}$ sensitivity to furosemide and bumetanide. $A, B$, Representative $/-V$ plot obtained from an SLIN before and after application of $100 \mu \mathrm{m}$ furosemide $(\boldsymbol{A})$ or $20 \mu \mathrm{m}$ bumetanide $(\boldsymbol{B})$. Application of furosemide shifted $E_{\text {IPSC }}$ from -62.3 to $-52.2 \mathrm{mV}$. Application of bumetanide shifted $E_{\text {IPS }}$ from -66.7 to $-72.0 \mathrm{mV}$. $A$, Inset, Example traces in control and in the presence of furosemide, respectively. $\boldsymbol{B}$, Inset, Example traces in the presence of bumetamide and in control, respectively. $C$, Average change in $/-V$ for SLIN in control (black squares; $E_{\mathrm{IPSC}}=-65.6 \pm 3.8 \mathrm{mV}$ ), in the presence of bumetanide (open circles; $E_{\mathrm{PSC}}=-81.9 \pm 4.1 \mathrm{mV}$ ), or in the presence of furosemide (open squares; $E_{\mathrm{PSC}}=-51.6 \pm 2.6 \mathrm{mV}$ ); from slices from P14-P17 mice, $n=5-7$. D, Plot of absolute change in $E_{\text {IPSC }}$ induced by bumetanide or furosemide (open symbols reflect individual experiments). Values $<0$ and $>0 \mathrm{mV}$ correspond to hyperpolarizing and depolarizing shifts in $E_{\mathrm{PPS}}$, respectively. At different development stages ( $\leq 10,12-16,18-25$, and $30-31)$, the average change in $E_{\text {IPSC }}$ was superimposed on the data (black-filled circles). $\boldsymbol{E}$, Furosemide and bumetanide was tested on PCs from young mice (P7-P9) or older mice (P18-P31). Values $<0$ and $>0 \mathrm{mV}$ correspond to a hyperpolarizing and depolarizing shift in the $E_{\text {IPS, }}$, respectively. Note that, in pyramidal cells, the effect of furosemide on $E_{\text {IPSC }}$ was significant $(p=0.029)$ only in older animals, whereas bumetanide only hyperpolarized $E_{\text {IPSC }}$ in young animals ( $p=0.034$ ), consistent with the known developmental expression of $\mathrm{KCC} 2$ and NKCC1, respectively. Error bars indicate SEM. Asterisks indicate $p<0.05$.

$V_{\text {rest }}$ was $-66.8 \pm 2.7 \mathrm{mV}(n=10)$ at $\mathrm{P} 8-\mathrm{P} 10$ and $-62.8 \pm 4.4$ $\mathrm{mV}(n=5)$ at $\mathrm{P} 30(p=0.43)$.

A comparison of $E_{\mathrm{IPSC}}$ and $V_{\text {rest }}$ in SLINs revealed that the driving force for inhibition at rest was maintained within $1-4 \mathrm{mV}$ across all ages measured (Fig. $2 G$ ), suggesting that inhibition onto CA3 SLINs was primarily shunting rather than hyperpolarizing in nature (Bartos et al., 2002). In contrast, CA3 PC IPSPs had a depolarizing driving force early in development $(+18.9 \pm$ $1.0 \mathrm{mV}$ at $\leq \mathrm{P} 10)$, which became hyperpolarizing during maturation $(-5.9 \pm 2.1,-9.9 \pm 1.3,-10.2 \pm 0.9 \mathrm{mV}$ at P12-P16, P18-P25, and P30-P31) (Fig. $2 H$ ), consistent with previous reports (Ben-Ari et al., 1989).

\section{The cotransporters NKCC1 and KCC 2 are not} developmentally regulated in SLINs

In immature PCs, expression of the NKCC1 transporter maintains an elevated level of intracellular $\left[\mathrm{Cl}^{-}\right]$and accounts for the positive IPSP driving force early in development (Ben-Ari, 2002).
During the first weeks of postnatal life, KCC2 expression increases, resulting in a lowering of intracellular $\left[\mathrm{Cl}^{-}\right]$, which is considered the primary determinant of the developmental IPSP polarity switch observed in PCs (Rivera et al., 1999; Yamada et al., 2004; Zhu et al., 2005). Whether a similar developmental switch in NKCC1 or KCC2 expression occurs in SLINs is not known.

Unfortunately, drugs that selectively block each transporter do not exist, although the loop diuretics bumetanide and furosemide are widely used to block either NKCC1 or KCC2, respectively. Bumetanide at low concentrations $(<20 \mu \mathrm{M})$ is relatively selective for NKCC1 (Payne, 1997; Russell, 2000; Dzhala et al., 2005) [although at this concentration it blocks recombinant KCC2 by $\sim 30 \%$ (Payne, 1997) ] and furosemide at $\leq 100 \mu \mathrm{M}$ is reasonably specific for KCC2 (Staley, 2002; Rivera et al., 2005). In P14-P17 SLINs, application of furosemide $(100 \mu \mathrm{M})$ routinely shifted $E_{\mathrm{IPSC}}$ to more positive potentials $(-51.6 \pm 2.6 \mathrm{vs}-65.6 \pm 3.8 \mathrm{mV}$ in control; $p=0.04 ; n=7$ ), presumably by an elevation of intracellular $\mathrm{Cl}^{-}$by unblocked NKCC1 activity (Fig. $3 A-C$ ). In contrast, in the presence of bumetanide $(20 \mu \mathrm{M})$, the $E_{\text {IPSC }}$ was shifted to more negative potentials $(-81.9 \pm 4.1 \mathrm{mV} ; n=$ $5 ; p=0.002)($ Fig. $3 B, C)$ consistent with a lowering of intracellular $\mathrm{Cl}^{-}$by residual KCC2 activity. For consistency, all measurements of the impact of both drugs were made $>10$ min after drug application, at a time point at which the effect on $E_{\text {IPSC }}$ had stabilized. These data suggest that the interplay between NKCC1 and KCC2 activity established the SLIN IPSP reversal potential close to $V_{\text {rest }}$ (Bartos et al., 2002).

Given the important role for the developmental regulation of KCC2 expression in establishing the pyramidal cell $E_{\mathrm{IPSC}}$, we next determined whether SLINs showed developmental changes in NKCC1 or KCC2 activity. Despite having opposing influence on $E_{\text {IPSC }}$, there was no significant change in the developmental sensitivity of SLINs to either furosemide or bumetanide between P7 and P31 (Fig. 3D). At P7-P10 and P28-P32, bumetanide caused a $-7.7 \pm$ $2.7 \mathrm{mV}(n=6)$ and $-2.1 \pm 3.5 \mathrm{mV}(n=5)(p=0.25)$ shift in $E_{\text {IPSC }}$, respectively. Similarly, furosemide caused a $4.5 \pm 1.8 \mathrm{mV}$ $(n=9)$ and $4.5 \pm 1.7 \mathrm{mV}(n=3)(p=0.21)$ shift in $E_{\text {IPSC }}$.

Out of concern for a potential lack of selectivity of bumetamide and furosemide for either cotransporter, we took advantage of the known development profile of NKCC1 and KCC2 in PCs and tested their effects at two developmental age ranges, P7-P9 and P18-P31. As predicted from the higher expression of NKCC1 in young compared with older animals, at P7-P9 bumetanide hyperpolarized the CA3 pyramidal cell $E_{\text {IPSC }}$ by $-2.8 \pm 1.0$ $\mathrm{mV}(n=6 ; p=0.04)$. In contrast, at P18-P31, bumetanide did not significantly change $E_{\mathrm{IPSC}}(0.5 \pm 2.1 \mathrm{mV} ; n=17 ; p=0.84)$, 
consistent with a downregulation of $\mathrm{NKCC} 1$ at this age. In pyramidal cells, KCC2 expression typically commences around the second postnatal week. Consistent with this expression pattern, furosemide depolarized the $E_{\mathrm{IPSC}}$ by $1.6 \pm 1.2 \mathrm{mV}(n=10 ; p=$ $0.21)$ at P7-P9 and by $6.4 \pm 2.9 \mathrm{mV}(n=16 ; p=0.03)$ at $\mathrm{P} 18-\mathrm{P} 31$. These data suggest that, at the concentrations used, in our hands furosemide and bumetanide are reasonably selective for KCC2 and NKCC1, respectively.

\section{Discussion}

Here, we demonstrate a clear distinction between the developmental regulation of inhibition onto CA3 SLINs compared with PCs and reveal that shunting inhibition predominates in SLINs throughout development. In contrast, a hyperpolarizing shift in the IPSC/P driving force results in a conventional inhibitory hyperpolarizing event in CA3 PCs across the same developmental range. Importantly, although the SLIN $E_{\mathrm{IPSC}}$ hyperpolarized throughout development, the change in $E_{\text {IPSC }}$ was tightly paralleled by a hyperpolarization of the resting membrane potential. The close association of the developmental regulation of both the resting potential and $E_{\text {IPSC }}$ resulted in a driving force for inhibition that was no more than a few millivolts across all ages tested. In contrast, PCs demonstrated a clear shift in chloride driving force, resulting in the now well established shift from depolarizing to hyperpolarizing GABAergic transmission on maturation (Ben-Ari, 2002).

The tight correlation between SLIN resting membrane potential and the $E_{\text {IPSC }}$ suggests that even small changes in either $V_{\text {rest }}$ or $E_{\text {IPSC }}$ could greatly impact $\mathrm{GABA}_{\mathrm{A}}$ receptor-mediated responses between local circuit interneurons. Interestingly, depolarizing or shunting GABA-mediated events have been reported in interneurons from several brain regions, including neocortex, hippocampus (dentate gyrus), dorsal cochlear nucleus, and cerebellum (Golding and Oertel, 1996; Martina et al., 2001; Bartos et al., 2002; Chavas and Marty, 2003). These data suggest that shunting inhibition may be a primary mechanism for inhibition onto interneurons rather than "conventional" hyperpolarization. Of course, until formally tested, we cannot rule out that other interneuron subpopulations use conventional hyperpolarization mechanisms. It is well established that $\mathrm{GABA}_{\mathrm{A}}$ receptormediated signaling in interneurons is essential for the generation of coherent oscillatory activity in hippocampal ensembles (Cobb et al., 1995; Jefferys et al., 1996; Wang and Buzsaki, 1996). However, in computer models of oscillations, $\mathrm{GABA}_{\mathrm{A}}$ receptormediated events have been mostly fixed as hyperpolarizing in nature, with little consideration for shunting inhibition or frequency dependent shifts in inhibitory synaptic polarity. Interestingly, recent data demonstrate that shunting inhibition may confer an increased robustness to hippocampal gamma oscillations (Bartos et al., 2002).

Previous studies have determined that, in hippocampal PCs, the two $\mathrm{Cl}^{-}$cotransporters, KCC2 and NKCC1, act to maintain the intracellular chloride concentration (Rivera et al., 1999; DeFazio et al., 2000; Gulyas et al., 2001; Hubner et al., 2001; Marty et al., 2002; Yamada et al., 2004; Wang et al., 2005; Zhu et al., 2005). In PCs, both cotransporters are developmentally regulated (Fukuda et al., 1998; Rivera et al., 1999; Yamada et al., 2004; Chudotvorova et al., 2005; Dzhala et al., 2005) with increased KCC2 transport expression being correlated with the developmental shift from depolarizing IPSPs to hyperpolarizing IPSPs (Rivera et al., 1999; Chudotvorova et al., 2005). Although both appear to have a role in controlling SLIN Cl${ }^{-}$homeostasis, neither KCC2 nor NKCC1 were regulated over the developmental window investigated, highlighting another important distinction between the regulation of PC and SLIN GABAergic transmission. Thus, in contrast to PCs, this indicates that both transporters are expressed at fairly constant levels in SLINs over development. However, these experiments cannot rule out the possibility that either cotransporter could be differentially regulated across the cells somato-dendritic-axonal axis. Although furosemide and bumetanide are typically considered poorly selective antagonists for KCC2 and NKCC1, respectively (Payne, 1997; Russell, 2000; Staley, 2002), in SLINs, furosemide always led to a depolarizing shift in the $E_{\text {IPSC }}$, whereas bumetanide routinely resulted in a hyperpolarizing shift in $E_{\text {IPSC }}$ consistent with their primary effects being on KCC2 and NKCC1 activity, respectively.

In conclusion, our data demonstrate that $\mathrm{GABA}_{\mathrm{A}}$ receptormediated inhibition onto SLINs is primarily shunting in nature, and importantly, unlike pyramidal cells, this inhibitory input does not undergo a depolarizing to hyperpolarizing developmental shift. The persistence of shunting inhibition throughout development suggests that inhibitory CA3 interneurons possess fundamentally different developmental rules than do their principal cell counterparts.

\section{References}

Bartos M, Vida I, Frotscher M, Meyer A, Monyer H, Geiger JRP, Jonas P (2002) Fast synaptic inhibition promotes synchronized gamma oscillations in hippocampal interneuron networks. Proc Natl Acad Sci USA 99:13222-13227.

Ben-Ari Y (2002) Excitatory actions of GABA during development: the nature of the nuture. Nat Rev Neurosci 3:728-739.

Ben-Ari Y, Cherubini E, Corradetti R, Gaiarsa J (1989) Giant synaptic potentials in immature rat CA3 hippocampal neurones. J Physiol (Lond) 416:303-325.

Chavas J, Marty A (2003) Coexistence of excitatory and inhibitory GABA synapses in the cerebellar interneuron network. J Neurosci 23:2019-2031.

Chudotvorova I, Ivanov A, Rama S, Hubner CA, Pellegrino C, Ben-Ari Y, Medina I (2005) Early expression of KCC2 in rat hippocampal cultures augments expression of functional GABA synapses. J Physiol (Lond) 566:671-679.

Cobb SR, Buhl EH, Halasy K, Paulsen O, Somogyi P (1995) Synchronization of neuronal activity in hippocampus by individual GABAergic interneurons. Nature 378:75-78.

DeFazio RA, Keros S, Quick MW, Hablitz JJ (2000) Potassium-coupled chloride cotransport controls intracellular chloride in rat neocortical pyramidal neurons. J Neurosci 20:8069-8076.

Dzhala V, Talos D, Sdrulla D, Brumback A, Mathews G, Benke T, Delpire E, Jensen F, Staley K (2005) NKCC1 transporter facilitates seizures in the developing brain. Nat Med 11:1205-1213.

Fukuda A, Muramatsu K, Okabe A, Shimano Y, Hida H, Fujimoto I, Nishino $\mathrm{H}$ (1998) Changes in intracellular $\mathrm{Ca}^{2+}$ induced by GABAA receptor activation and reduction in $\mathrm{Cl}^{-}$gradient in neonatal rat neocortex. J Neurophysiol 79:439-446.

Golding N, Oertel D (1996) Context-dependent synaptic action of glycinergic and GABAergic inputs in the dorsal cochlear nucleus. J Neurosci 16:2208-2219.

Gulyas AI, Sik A, Payne JA, Kaila K, Freund TF (2001) The KCl cotransporter, KCC2, is highly expressed in the vicinity of excitatory synapses in the rat hippocampus. Eur J Neurosci 13:2205-2217.

Henze DA, Wittner L, Buzsaki G (2002) Single granule cells reliably discharge targets in the hippocampal CA3 network in vivo. Nat Neurosci 5:790-795.

Hubner CA, Stein V, Hermans-Borgmeyer I, Meyer T, Ballanyi K, Jentsch TJ (2001) Disruption of KCC2 reveals an essential role of $\mathrm{K}-\mathrm{Cl}$ cotransport already in early synaptic inhibition. Neuron 30:515-524.

Jefferys JGR, Traub RD, Whittington MA (1996) Neuronal networks for induced "40 Hz" rhythms. Trends Neurosci 19:202-208.

Kyrozis A, Reichling DB (1995) Perforated-patch recording with gramicidin avoids artifactual changes in intracellular chloride concentration. J Neurosci Methods 57:27-35.

Lawrence JJ, McBain CJ (2003) Interneuron diversity series: containing the 
detonation-feedforward inhibition in the CA3 hippocampus. Trends Neurosci 26:631-640.

Lawrence JJ, Grinspan ZM, McBain CJ (2004) Quantal transmission at mossy fibre targets in the CA3 region of the rat hippocampus. J Physiol (Lond) 554:175-193.

Martina M, Royer S, Pare D (2001) Cell-type-specific GABA responses and chloride homeostasis in the cortex and amygdala. J Neurophysiol 86:2887-2895.

Marty S, Wehrle R, Alvarez-Leefmans FJ, Gasnier B, Sotelo C (2002) Postnatal maturation of $\mathrm{Na}^{+}, \mathrm{K}^{+}, 2 \mathrm{Cl}$ cotransporter expression and inhibitory synaptogenesis in the rat hippocampus: an immunocytochemical analysis. Eur J Neurosci 15:233-245.

McBain C, Fisahn A (2001) Interneurons unbound. Nat Rev Neurosci 2:11-23.

Mori M, Abegg MH, Gahwiler BH, Gerber U (2004) A frequencydependent switch from inhibition to excitation in a hippocampal unitary circuit. Nature 431:453-456.

Payne JA (1997) Functional characterization of the neuronal-specific K-Cl cotransporter: implications for $\left[\mathrm{K}^{+}\right]_{\mathrm{o}}$ regulation. Am J Physiol 273:C1516-C1525.

Pouille F, Scanziani M (2001) Enforcement of temporal fidelity in pyramidal cells by somatic feed-forward inhibition. Science 293:1159-1163.

Rivera C, Voipio J, Payne JA, Ruusuvuori E, Lahtinen H, Lamsa K, Pirvola U, Saarma M, Kaila K (1999) The $\mathrm{K}^{+} / \mathrm{Cl}^{-}$co-transporter KCC2 renders GABA hyperpolarizing during neuronal maturation. Nature 397:251-255.
Rivera C, Voipio J, Kaila K (2005) Two developmental switches in GABAergic signalling: the $\mathrm{K}^{+}-\mathrm{Cl}^{-}$cotransporter $\mathrm{KCC} 2$ and carbonic anhydrase CAVII. J Physiol (Lond) 562:27-36.

Russell JM (2000) Sodium-potassium-chloride cotransport. Physiol Rev $80: 211-276$.

Staley K (2002) Diuretics as antiepileptic drugs: should we go with the flow? Epilepsy Curr 2:35-38.

Toth K, McBain CJ (1998) Afferent-specific innervation of two distinct AMPA receptor subtypes on single hippocampal interneurons. Nat Neurosci 1:572-578.

Verheugen JAH, Fricker D, Miles R (1999) Noninvasive measurements of the membrane potential and GABAergic action in hippocampal interneurons. J Neurosci 19:2546-2555.

Wang C, Ohno K, Furukawa T, Ueki T, Ikeda M, Fukuda A, Sato K (2005) Differential expression of KCC2 accounts for the differential GABA responses between relay and intrinsic neurons in the early postnatal rat olfactory bulb. Eur J Neurosci 21:1449-1455.

Wang X-J, Buzsaki G (1996) Gamma oscillation by synaptic inhibition in a hippocampal interneuronal network model. J Neurosci 16:6402-6413.

Yamada J, Okabe A, Toyoda H, Kilb W, Luhmann HJ, Fukuda A (2004) $\mathrm{Cl}^{-}$ uptake promoting depolarizing GABA actions in immature rat neocortical neurones is mediated by NKCC1. J Physiol (Lond) 557:829-841.

Zhu L, Lovinger D, Delpire E (2005) Cortical neurons lacking KCC2 expression show impaired regulation of intracellular chloride. J Neurophysiol 93:1557-1568. 